\title{
Marta Van Rysselberghe, Je ne sais si nous avons dit d'impérissables choses
}

\section{Emanuele Kanceff}

\section{(2) OpenEdition}

1 Journals

\section{Edizione digitale}

URL: https://journals.openedition.org/studifrancesi/46215

DOI: 10.4000/studifrancesi.46215

ISSN: 2421-5856

\section{Editore}

Rosenberg \& Sellier

\section{Edizione cartacea}

Data di pubblicazione: 1 octobre 2007

Paginazione: 473

ISSN: 0039-2944

\section{Notizia bibliografica digitale}

Emanuele Kanceff, «Marta Van Rysselberghe, Je ne sais si nous avons dit d'impérissables choses», Studi Francesi [Online], 152 (LI | II) | 2007, online dal 30 novembre 2015, consultato il 24 novembre 2021. URL: http://journals.openedition.org/studifrancesi/46215; DOI: https://doi.org/10.4000/studifrancesi. 46215

Questo documento è stato generato automaticamente il 24 novembre 2021.

\section{(c)}

Studi Francesi è distribuita con Licenza Creative Commons Attribuzione - Non commerciale - Non opere derivate 4.0 Internazionale. 


\title{
Marta Van Rysselberghe, Je ne sais si nous avons dit d'impérissables choses
}

\author{
Emanuele Kanceff
}

\section{NOTIZIA}

MARTA VAN RYSSELBERGHE, Je ne sais si nous avons dit d'impérissables choses. Une anthologie des Cahiers de la Petite Dame. Choix et présentation de Peter SCHNYDER, Paris, Gallimard, 2006 (Coll. "Folio", 4425), pp. 704.

1 Dopo l'edizione integrale di Claude Martin e le riedizioni nei «Cahiers de la NRF», l'ultra-trentennale diario quotidiano della Petite Dame non è più una novità per il lettore. Del resto il titolo qui abbreviato suona in modo differente se letto in modo integrale: «Je ne sais si nous avons dit d'impérissables choses, mais je sais qu'elles étaient toujours du plus vif intérêt et que je me sentais assez délassée quand Gide n'était pas là, par l'idée de ne pas devoir les retenir à la lettre».

2 Si direbbe che, detto tutto sul maestro, l'interesse degli studiosi si stia spostando ormai sul suo mondo, su quanti lo conobbero, lo frequentarono, ne lasciarono più o meno alata testimonianza, ed è venuta la volta di Maria, cui un noto specialista gidiano, Peter Schnyder, curatore del volume, dedica una folta ed erudita introduzione, quasi a volersi far perdonare dall'interessata per aver compiuto un'operazione che l'autrice non avrebbe approvata: una scelta di testi. Tuttavia, recriminazioni della Petite Dame a parte, questa scelta, tenuta nei limiti di un rigore critico sicuro, non nuoce né all'opera né ai suoi lettori, che meglio si orientano qui di quanto non farebbero nelle oltre 3000 pagine dell'originale. 